\section{Analisis Efektifitas Simpang Tak Besinyal Jalan Sekumpul - Jalan Tanjung Rema Martapura}

\author{
Robiatul Adawiyah ${ }^{1}$ Gusti Akmalia Sari ${ }^{2}$ \\ ${ }^{1}$ Dosen Jurusan Teknik Sipil, Fakultas Teknik Universitas \\ Islam Kalimantan Muhammad Arsyad Al-Banjari \\ Banjarmasin. Jl. Adhiyaksa No. 2, Kayu Tangi, Kota \\ Banjarmasin, Kalimantan Selatan 70123 Indonesia \\ ${ }^{2}$ Mahasiswa Jurusan Teknik Sipil, Fakultas Teknik \\ Universitas Islam Kalimantan Muhammad Arsyad Al- \\ Banjari, Banjarmasin.
}

$\triangle \quad$ awe_halis@yahoo.com

\begin{abstract}
Kemacetan pada persimpangan jalan Sekumpul jalan Sekumpul Ujung - jalan Guntung Alaban -Jalan Tanjung Rema Martapura semakin meningkat dikarenakan pada persimpangan itu belum mempunyai lampu sinyal, ditambah lagi adanya pasar tradiasional pada ruas jalan tersebut serta banyaknya penziarah ke Kubah Guru Sekumpul, dan sering pula terjadi kecelakaan akibat tidak adanya system yang mengatur persimpangan tersebut. Penelitian ini bertujuan untuk menganalisa lalu lintas pada persimpangan tersebut untuk mendapatkan kinerja simpang dengan mengunakan Metode MKJI (Manual Kapasitas Jalan Indonesia) 1997. Survei dilakukan selama tiga hari yaitu hari Rabu, Kamis dan Jum'at pada pukul o6.0o-22.0o. Dari hasil survei tersebut didapat Arus Lalu Lintas (Q) terbesar yaitu 2708 smp/jam dengan nilai Derajat Kejenuhan (DS) = 1,140685 dan Indeks Tingkat Pelayanan termasuk dalam kelas E, maka persimpangan ini sangat melampaui batas yang diizinkan.
\end{abstract}

Kata kunci Jalan, MKJI, Simpang, Sinyal

DIpresentasikan: 30 Agustus 2019

Direvisi: 14 September 2019

Diterima: 2 Oktober 2019

Dipublikasikan online: 5 Oktober 2019

\section{Pendahuluan}

Lalu lintas di jalan raya ditimbulkan oleh adanya pergerakan dari alat-alat angkutan, sedangkan kegiatan angkutan itu sendiri timbul karena adanya kebutuhan akan pepindahan manusia dan barang. Transportasi merupakan bagian terpenting dari kehidupan sehari-hari, namun masih mengalami berbagai masalah dan masalah yang sering ditimbulkan oleh transportasi adalah akan semakin terasa pada saat orang melakukan perjalanan dengan tujuan dan waktu yang bersamaan. Kemacetan pada persimpangan jalan Sekumpul - jalan Sekumpul Ujung - jalan Guntung Alaban-Jalan Tanjung Rema Martapura semakin meningkat dikarenakan pada persimpangan itu belum mempunyai lampu sinyal, ditambah lagi adanya pasar tradiasional pada ruas jalan tersebut serta banyaknya penziarah ke Kubah Guru Sekumpul, dan sering pula terjadi kecelakaan akibat tidak adanya system yang mengatur persimpangan tersebut. Penelitian ini bertujuan untuk menganalisa lalu lintas pada persimpangan tersebut untuk mendapatkan kinerja simpang dengan mengunakan Metode MKJI (Manual Kapasitas Jalan Indonesia) 1997.

Adapun penelitian yang menggunakan Metode MKJ seperti Adawiyah (2017) menganalisis efektivitas kinerja fly over pada simpang bersinyal. Dengan menggunakan metode MKJI maka didapatkan kinerja simpang dengan perhitungan secara manual dan lebih detail.

\section{Metode}

Pada penelitian ini dilakukan survei LHR selama 3 (tiga) hari pada hari Rabu - Jum'at karena pada pelaksanaan survei dapat dilakukan penyederhanaan yang kemudian dapat dikonversikan untuk mendapatkan lalu lintas harian rata-rata dan jam terpuncak pada lalu lintas tersebut. Dan survei dilakukan pada hari Rabu - Jum'at karena merupakan hari normal untuk aktivitas di wilayah perkotaan sedangkan hari Sabtu sebagian perkantoran libur dan hari Minggu mempunyai ciri tersendiri yang sangat terpengaruh dengan kegiatan dikawasan yang dilakukan survei. Bagan alir dan lokasi penelitian masing-masing terlihat pada Gambar 1 dan 2.

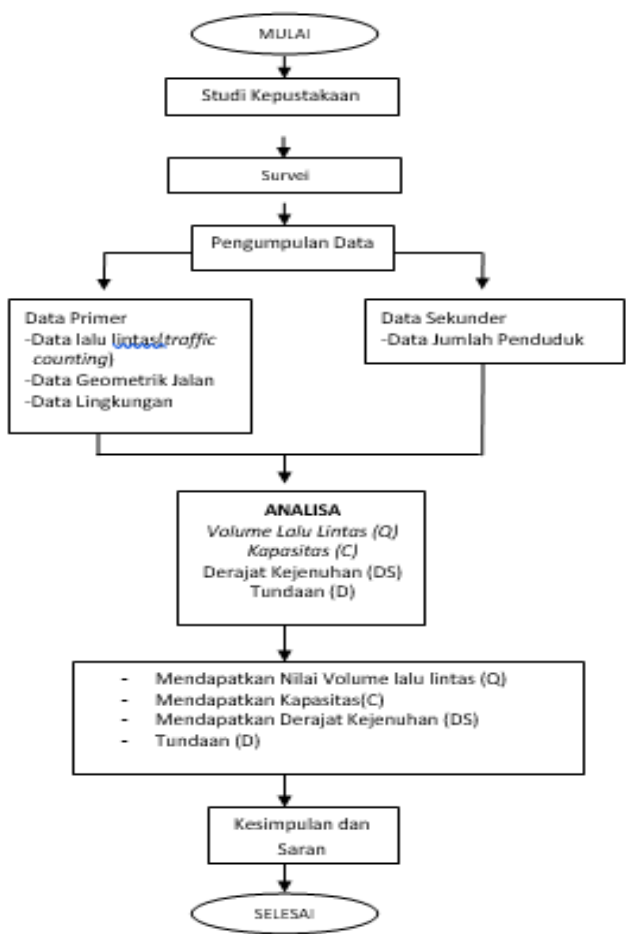

Gambar 1 Bagan Alir Penelitian

Cara mensitasi artikel ini:

Adawiyah, R., Sari, G. A. (2019) Analisis Efektifitas Simpang Tak Besinyal Jalan Sekumpul - Jalan Tanjung Rema Martapura. [Edisi Khusus]. Buletin Profesi Insinyur 2(3): 118-121 


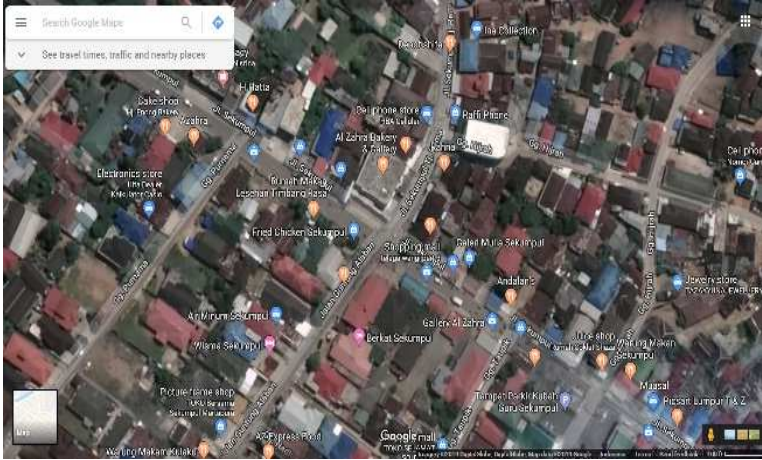

Gambar 2. Peta Lokasi Penelitian

\section{Hasil dan Analisis}

Berdasarkan jumlah penduduk BPS Provinsi Kalimantan Selatan Hasil Proyeksi Penduduk Pertengahan 2018 jumlah penduduk kota Martapura Kota adalah 112.616 jiwa dengan pria sebesar 57.494 jiwa, perempuan sebesar 55.122 jiwa.

Contoh perhitungan volume lalu lintas:

Perhitungan data lalu lintas setiap kendaraan /10 menit Diketahui volume sepeda motor pada pukul 06.0006.10 dari arah Sekumpul - Guntung Alaban adalah sebesar 2 unit.

Dan nilai EMP untuk sepeda motor $=0,5$

Volume MC per 10 menit

$=2$ unit $\times 0,5$

$=1 \mathrm{smp} / 10 \mathrm{mnt}$

Gambar 3, 4 dan 5 merupakan sebagian grafik dari volume lalu lintas yang didapat dari hasil survei yang sudah diolah menjadi smp/jam.

\section{Arus Lalu Lintas (Q)}

Jalan Utama A - C (Jalan Sekumpul dan jalan Sekumpul Ujung )

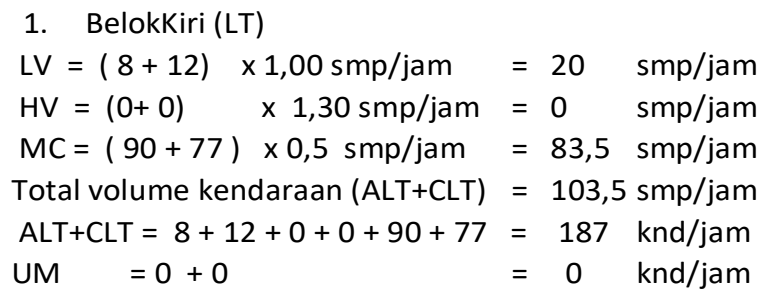

Jalan Minor B - D (Jalan Guntung Alaban dan Jalan Tanjung Rema )

1. Belok Kiri (LT)

$\mathrm{LV}=(9+9) \quad \times 1,00 \mathrm{smp} / \mathrm{jam}=18 \mathrm{smp} / \mathrm{jam}$

$\mathrm{HV}=(0+0) \quad \times 1,30 \mathrm{smp} / \mathrm{jam}=0 \mathrm{smp} / \mathrm{jam}$

$\mathrm{MC}=(197+662) \quad \times 0,5 \mathrm{smp} / \mathrm{jam}=429,5 \mathrm{smp} / \mathrm{jam}$ Total volume kendaraan $(B L T+D L T)=447,5 \mathrm{smp} / \mathrm{jam}$ $\mathrm{BLT}+\mathrm{DLT}=9+9+0+0+197+662=877 \mathrm{knd} / \mathrm{jam}$ $\mathrm{UM}=2+4=6 \mathrm{knd} / \mathrm{jam}$

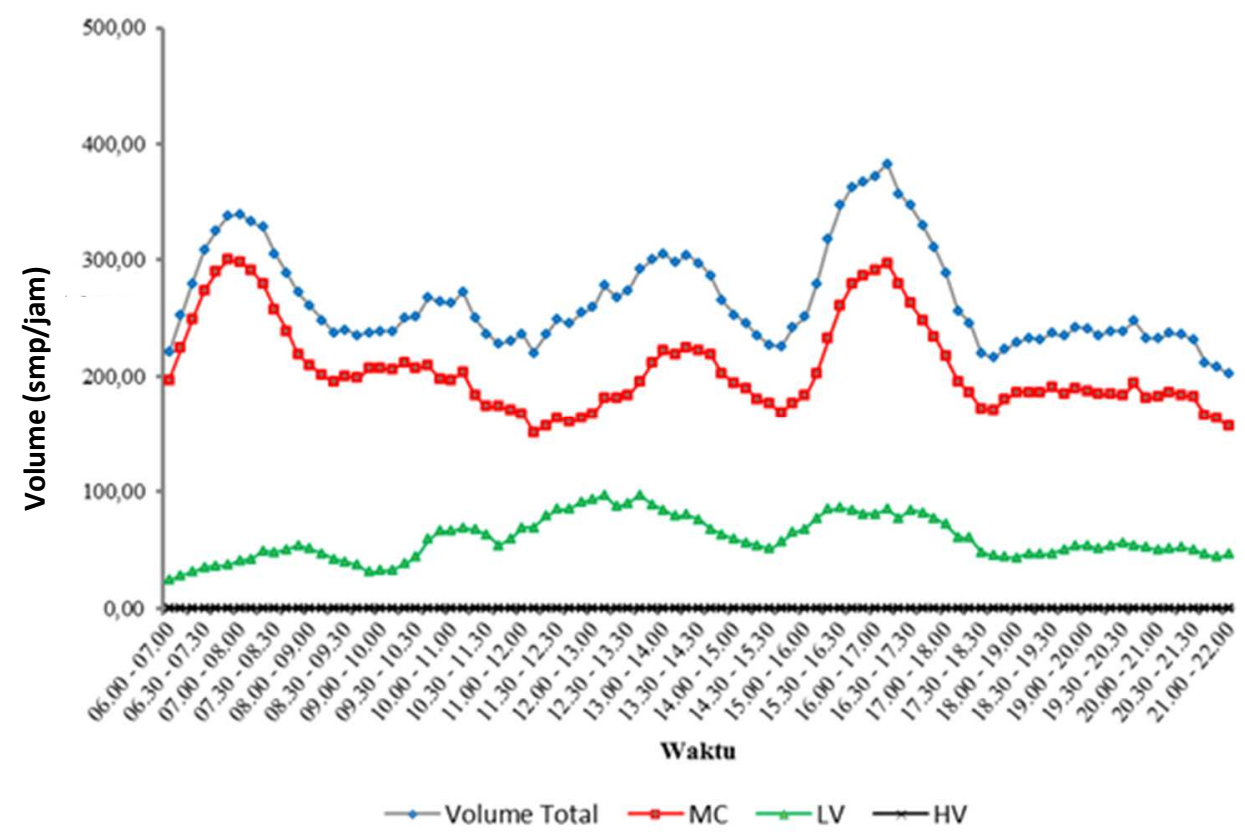

Gambar 3. Volume Lalu Lintas dari Arah Sekumpul ke Sekumpul ujung 


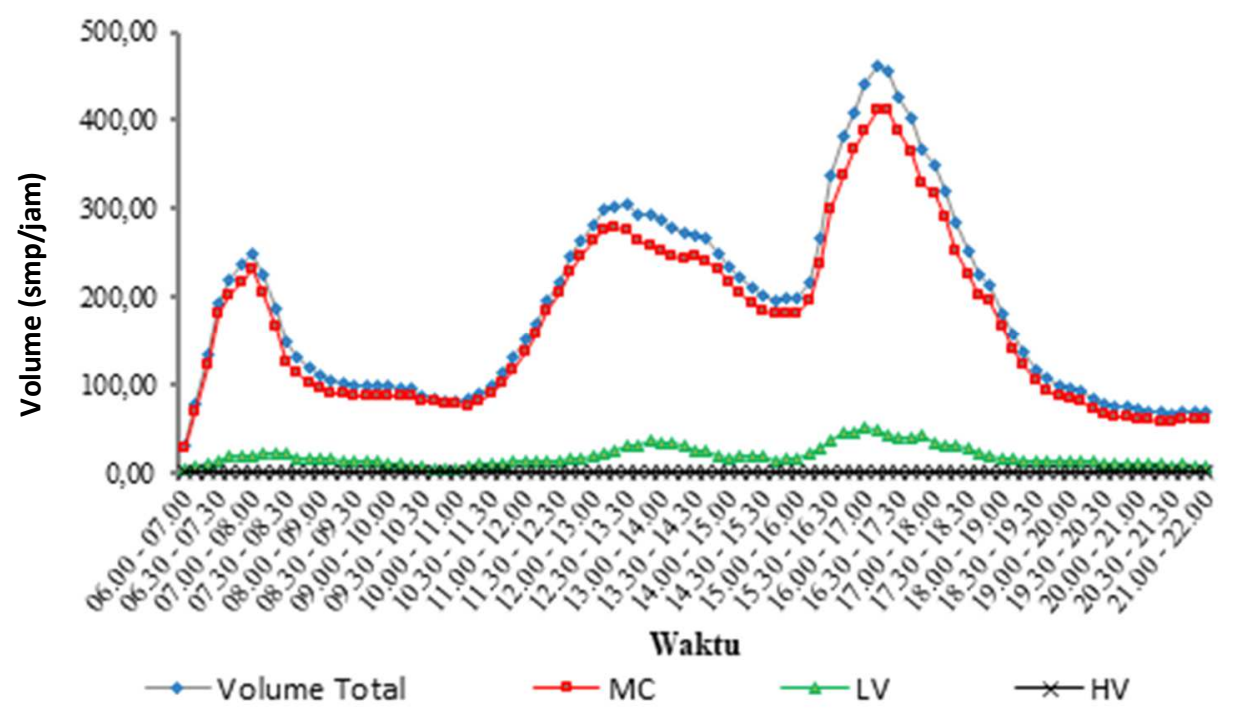

Gambar 4. Volume Lalu Lintas dari Guntung Alaban ke Tanjung Rema

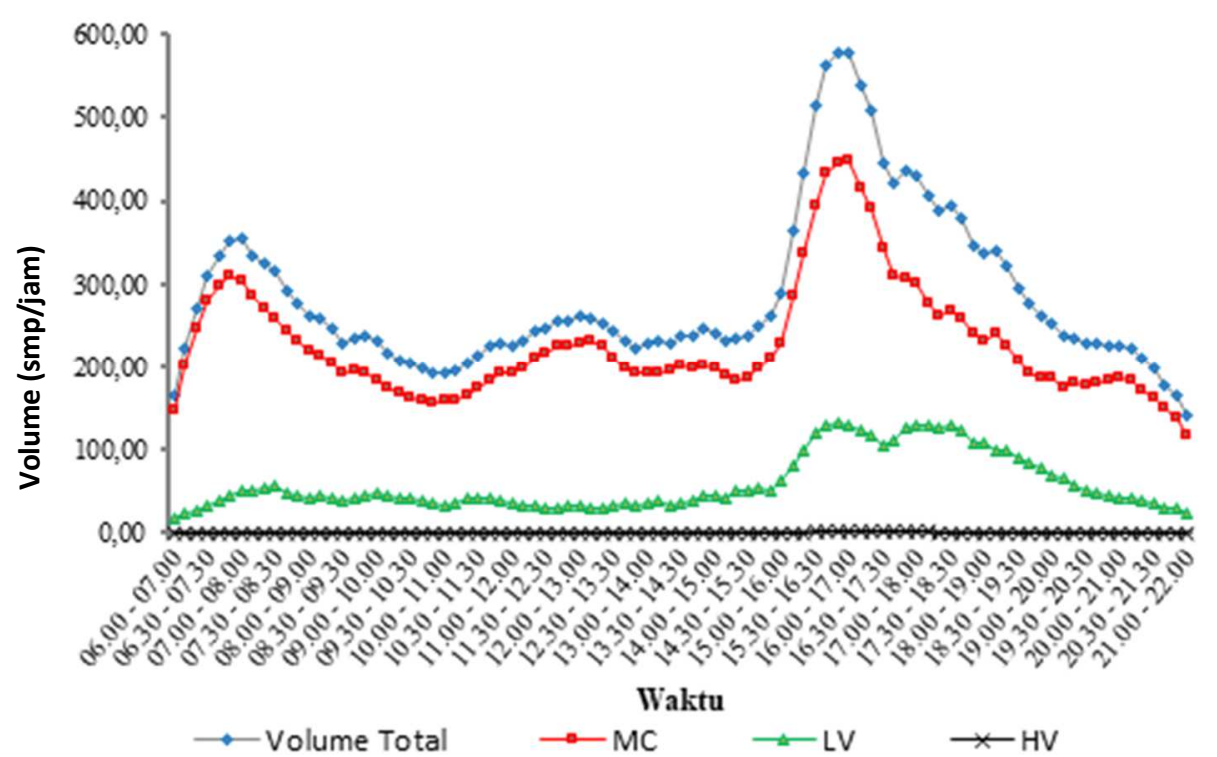

Gambar 5. Volume Lalu Lintas dari Sekumpul Ujung ke Sekumpul

2. Lurus (ST)

\begin{tabular}{|c|c|c|c|c|}
\hline$L V=(52+6)$ & $\times 1,00$ & $\mathrm{smp} / \mathrm{jam}=$ & 58 & smp/jam \\
\hline$H V=(0+0)$ & x 1,30 & $\mathrm{smp} / \mathrm{jam}=$ & 0 & smp/jam \\
\hline$M C=(778+440)$ & $x 0,5$ & $\mathrm{smp} / \mathrm{jam}=$ & 609 & smp/jam \\
\hline Total volume kend & daraan (B & $3 S T+D S T)=$ & 677 & smp/jam \\
\hline$S T+D S T=52+6$ & $+0+c$ & $778+440=$ & $=1278$ & $3 \mathrm{knd} / \mathrm{jam}$ \\
\hline $\mathrm{UM}=9+4$ & & $=$ & 13 & $\mathrm{knd} / \mathrm{jam}$ \\
\hline \multicolumn{5}{|l|}{ 3.Belok Kanan (RT) } \\
\hline$L V=(11+4)$ & $\times 1,00$ & $\mathrm{smp} / \mathrm{jam}=$ & 15 & smp/jam \\
\hline$H V=(0+0)$ & $\times 1,30$ & $\mathrm{smp} / \mathrm{jam}=$ & 0 & smp/jam \\
\hline$M C=(80+13)$ & $\times 0,5$ & $\mathrm{smp} / \mathrm{jam}=$ & 46,5 & smp/jam \\
\hline Total volume kend & daraan & (RT+DRT) $=$ & 61,5 & smp/jam \\
\hline $\mathrm{BRT}+\mathrm{DRT}=11+4$ & $+0+$ & $80+13=$ & 108 & $\mathrm{knd} / \mathrm{jam}$ \\
\hline$U M=1+0$ & & $=$ & 1 & $\mathrm{knd} / \mathrm{jam}$ \\
\hline
\end{tabular}

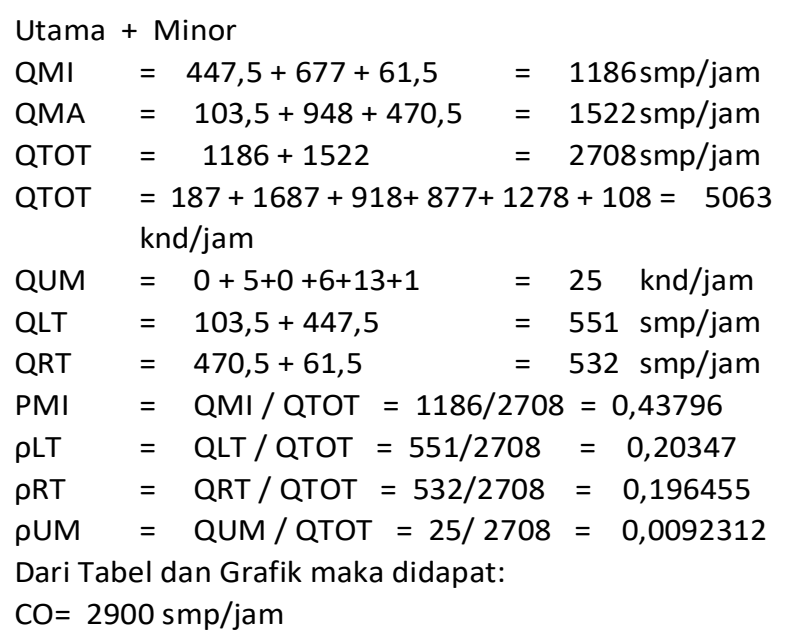


Ringkasan untuk perhitungan kapasitas dirangkum pada Tabel 1.

Tabel 1. Data untuk Perhitungan Kapasitas

\begin{tabular}{ll}
\hline Parameter & Nilai \\
\hline CO & $2900 \mathrm{smp} /$ jam \\
FW & 0,93208 \\
FM & 1,00 \\
FCS & 0,94 \\
FRSU & 0,8920384 \\
FLT & 1,1675867 \\
FRT & 1,00 \\
FMI & 0,897080 \\
\hline
\end{tabular}

(Sumber : MKJI 1997)

$$
\begin{aligned}
& \mathrm{C}=\mathrm{CO} \times \mathrm{FW} \times \mathrm{FM} \times \mathrm{FCS} \times \mathrm{FRSU} \times \mathrm{FLT} \times \mathrm{FRT} \times \mathrm{FMI} \\
&=2900 \times 0,93208 \times 1,00 \times 0,94 \times 0,8920384 \times \\
& 1,1675867 \times 1,00 \times 0,897080=2374,0119 \mathrm{smp} / \mathrm{jam}
\end{aligned}
$$

Diketahui : QTOT $=2708 \mathrm{smp} / \mathrm{jam}$

$\mathrm{DS}=\mathrm{QTOT} / \mathrm{C}=2708 / 2374,0119=1,140685(\mathrm{DS}>0,85)$

Tundaan Lalu Lintas Simpang (DT1)

DT $1=1,0504 /(0,2742-(0,2042 \times 1,140685))-(1-$ $1,140685) \times 2$

DT1 $=25,8559 \mathrm{det} / \mathrm{smp}$

Tundaan Lalu Lintas Utama (DTma)

Dtma = 1.05034/(0,3046- $(0,246 \times 1,140685))-(1-$

$1,140685) \times 1,8$

DTma $=44,03292$ det $/ \mathrm{smp}$

Tundaan Lalu Lintas Jalan Minor (DMI)

DMI $=($ QTOT $\times$ DTI - QMA $\times$ DTMA $) /$ QMI

$D M I=(2708 \times 25,8559-1522 \times 44,03292) / 1186$

$\mathrm{DMI}=2,52923 \mathrm{det} / \mathrm{smp}$

Tundaan Geometrik Simpang (DG)

DS $<1$ maka digunakan rumus berikut :

$\mathrm{DG}=(1-\mathrm{DS}) \times\left(\mathrm{P}_{\mathrm{T}} \times 6+\left(1-\mathrm{P}_{\mathrm{T}}\right) \times 3\right)+\mathrm{DS} \times 4$ Sedangkan $\mathrm{DS} \geq 1$ maka $\mathrm{DG}=4$
Tundaan Simpang

$$
\begin{aligned}
& D=D G+D T I \\
& D=4+25,8559 \\
& D=29,8559 \mathrm{det} / \mathrm{smp}
\end{aligned}
$$

Dari Tabel dan Grafik maka didapat:

\section{Kesimpulan}

Dari hasil penelitian dapat disimpulkan yaitu :

1. Arus lalu lintas $(Q)$ terbesar terjadi pada hari Kamis Jam 15.50-16.50 yaitu 2708 smp/jam dengan Derajat Kejenuhan (DS) sebesar 1,140685 Tundaan Lalu Lintas Simpang (DT1) sebesar 25,8559 det/smp. Tundaan Lalu Lintas Jalan Utama (Dtma) sebesar 44,03292det /smp, Tundaan Lalu Lintas Jalan Minor ( DMI) sebesar 2,52923 det/smp, Tundaan Geometrik Simpang (DG) sebesar 4 det/smp, Tundaan Simpang ( D ) sebesar 29,8559 det/smp.

2. Tingkat pelayanan pada persimpangan tersebut adalah E yang mana arus lalu lintas sudah tidak stabi dan sering terjadi kemacetan

\section{Ucapan Terimakasih}

Terima kasih kepada Universitas Islam Kalimantan Muhammad Arsyad Al-Banjari Banjarmasin atas bantuan dalam penelitian ini.

\section{Referensi}

Jotin Khristy, C \& Kent Lalll, B (2005) Dasar-Dasar Rekayasa Transportasi (terjemahan). Erlangga. Jakarta.

Manual Kapasitas Jalan Indonesia (MKJI) (1997) Direktorat Jenderal Bina Marga. Direktorat Pembangunan Jalan Perkotaan, Jakarta.

Radam., I. F (2008) Rekayasa Lalu Lintas. Universitas Lambung Mangkurat Press.Banjarmasin.

Adawiya, R (2017) Analisis Efektivitas Kinerja Fly Over pada Simpang Bersinyal Gatot Subroto Banjarmasin. Jurnal Transukma, Juni 2017, ISSN 2502-1028. 